\title{
PERAN CITRA MEREK MEMEDIASI PENGARUH IKLAN TERHADAP KEPUTUSAN PEMBELIAN ES KRIM WALL'S MAGNUM
}

\author{
Ni Putu Jessica Maharani Putri ${ }^{1}$ \\ Ni Made Wulandari Kusumadewi ${ }^{2}$
}

\author{
${ }^{1,2}$ Fakultas Ekonomi Dan Bisnis Universitas Udayana, Bali, Indonesia \\ e-mail: jessicaputrii.10@gmail.com
}

\begin{abstract}
ABSTRAK
Perkembangan dunia periklanan saat ini terus meningkat, sehingga membuat perusahaan harus selektif dalam membuat iklan yang kreatif dan menarik untuk memberikan citra merek yang dapat menarik konsumen dalam keputusan pembelian. Tujuan Penelitian ini dilakukan untuk mengetahui peran citra merek memediasi pengaruh iklan terhadap keputusan pembelian es krim Wall's Magnum. Penelitian ini dilakukan di Kecamatan Kuta. Jumlah sampel yang diambil sebanyak 100 sampel dengan metode nonprobability sampling. Pengumpulan data dilakukan melalui kuesioner dengan skala likert 1-5. Teknik analisis yang digunakan adalah analisis jalur (Path analysis). Berdasarkan hasil analisis ditemukan bahwa iklan berpengaruh positif terhadap citra merek, citra merek berpengaruh positif terhadap keputusan pembelian, iklan berpengaruh positif terhadap keputusan pembelian dan citra merek memediasi pengaruh iklan terhadap keputusan pembelian. Saran bagi perusahaan, jika ingin meningkatkan keputusan pembelian harus memperhatikan iklan dan citra merek. Saran bagi peneliti selanjutnya adalah agar meneliti menggunakan variabel selain pengaruh iklan, citra merek untuk meneliti keputusan pembelian.
\end{abstract}

Kata kunci: citra merek, iklan, keputusan pembelian

\begin{abstract}
The current development of the advertising world continues to increase, making the company selectiv in creating creative and engaging advertisements to provide a brand image that can attract consumers in purchasing decisions. The purpose of this study was to determine the role of brand image mediating the influence of advertising on purchasing decisions of Wall's Magnum ice cream. This research was conducted in Kecamatan Kuta. The number of samples taken as many as 100 samples with nonprobability sampling method. The data was collected through questionnaires with likert scale 1-5. The analysis technique used is path analysis (Path analysis). Based on the results of the analysis found that ads have a positive effect on brand image, brand image positively affects purchasing decisions, advertising positively affects purchasing decisions and brand image mediates the effect of advertising on purchasing decisions. Advice for companies, if you want to improve purchasing decisions should pay attention to advertising and brand image. Suggestions for future researchers are to research using variables other than the influence of advertising, brand image to examine purchasing decisions.
\end{abstract}

Keywords: brand image, advertisement, purchase decision 


\section{PENDAHULUAN}

Pemasaran merupakan salah satu kegiatan untuk merencanakanapa yang harus dilakukan oleh perusahaan untuk mempertahankan kelangsungan hidupnya dan memperkuat posisi dalam menghadapi pesaing untuk mendapatkan laba (Khasanah, 2011). Hal tersebut disebabkan karena pemasaran merupakan salah satu kegiatan perusahaan, dimana secara langsung berhubungan dengan konsumen. Sehingga kegiatan pemasaran merupakan kegiatan manusia yang memiliki kaitan langsung dengan pasar. Dengan adanya pemasaran yang baik dapat menjadi kunci kesuksesan dari suatu perusahaan.

Perkembangan dunia periklanan saat ini semakin pesat yang didukung oleh pertumbuhan media cetak atau media elektronik yang terus meningkat, sehingga membuat perusahaan harus selektif dalam membuat iklan untuk mendukung penjualannya. Strategi pemasaran dan promosi yang tepat dan efisien diperlukan agar efektivitas komunikasi iklan dapat tercapai. Promosi adalah suatu komunikasi informasi penjual dan pembeli yang dilakukan oleh perusahaan dengan cara mempengaruhi konsumen secara langsung ataupun tidak langsung. Bagaimanapun kualitas produk, apabila konsumen tidak mengetahui dan tidak yakin bahwa produk itu akan berguna untuk mereka, maka mereka tidak akan pernah membelinya (Purnamasari, 2015).

Periklanan adalah alat yang digunakan untuk memberikan informasi tentang suatu produk. Periklanan merupakan metode promosi yang dapat dikategorikan paling efektif dibandingkan dengan metode promosi lainnya. Perusahaan bisa mempromosikan produknya menggunakan berbagai media cetak maupun 
elektronik seperti televisi, majalah, koran, baliho, iklan di internet dan lainnya, media yang paling efektif dibandingkan media iklan lainnya adalah televisi (Mariyanti, 2015).

Meningkatnya persaingan di zaman yang modern ini membuat para pengusaha berusaha lebih lagi dalam mendapatkan konsumen tidak hanya terbatas pada kegunaan produk saja tetapi juga berkaitan dengan merek yang mampu memberikan citra khusus bagi konsumen (Pujiadi, 2010). Perusahaan harus menciptakan strategi bauran pemasaran yang lebih kreatif dan inovatif agar produk dan jasa tersebut memiliki citra merek (brand image) bagi konsumen. Konsumen dengan citra positif terhadap suatu merek, lebih memungkinkan untuk melakukan pembelian (Setiadi, 2013).

Konsumen yang orientasi pembeliannya bertumpu pada prinsip dikatakan lebih rasional karena dalam mengambil keputusan membeli didasarkan pada keyakinan bukan karena ikut-ikutan atau sekedar untuk dihargai atau dihormati. Sedangkan yang berhubungan dengan emosional, keputusannya dalam membeli didominasi oleh orang lain. Produk-produk yang bermerek biasanya menjadi pilihan yang tidak berpikir tentang manfaatnya (Pratiwi, 2015).

Rangsangan dari perusahaan sangat diperlukan karena merupakan salah satu faktor penting yang dapat mempengaruhi pengambilan keputusan produk. Setiap perusahaan harus merancang strategi yang tepat guna memenangkan keputusan pembelian tersebut (Fatlahah, 2013). Keputusan pembelian konsumen terhadap sebuah produk sangat penting karena dengan melakukan pembelian, maka evaluasi paska pembelian terjadi (Kotler, 2007). 
Keputusan pembelian merupakan hasil dimana konsumen merasa mengalami masalah dan kemudian melalui proses rasional menyelesaikan masalah tersebut (Dewi, 2013). Fatlahah (2013) menyatakan bahwa citra merek akan menjadi pertimbangan penting bagi pembelian. Rijswijk (2008) mengatakan bahwa bauran pemasaran mempengaruhi citra merek suatu produk, yang juga menjadi pertimbangan konsumen dalam menentukan produk.

Kekuatan merek terletak pada kemampuannya mengikat konsumen untuk membeli produk yang diinginkannya (Goenawan, 2014). Merek sangat penting bagi perusahaan untuk menunjukkan nilai produk yang di tawarkan ke pasar, tetapi mereka tidak akan berarti jika tidak memiliki citra yang kuat bagi pasar. Bagi perusahaan yang sadar akan makna penting dan strateginya merek, citra merek menjadi hal yang selalu diperhatikan karena citra merek dianggap sebagai tambahan arus kas yang diperoleh melalui pengaitan nama merek dengan produk atau jasa yang mendasarinya. Sebuah merek yang terkenal dan terpercaya merupakan aset yang tak ternilai karena dapat menyebabkan minat beli konsumen yang tinggi.

Di zaman yang modern ini terdapat beberapa produk olahan yang terbuat dari susu seperti es krim, yoghurt, permen, milkshake, dll. Es Krim Wall's adalah merek makanan asal Inggris yang dimiliki oleh Uniliver, perusahaan ini didirikan di London pada tahun 1786 oleh Terence Banyard. Wall's memproduksi berbagai es krim pada tahun 1922, wall's memiliki beberapa produk, yaitu Paddle Pop, Feast, Popolaire, Wall's Ice Cream Sandwich, Shakey Shake, Cornetto, Wall's Selection, Neopolitana dan Magnum. 
Khusus untuk merek produk es krim Wall's Magnum pemasaran yang dilakukan adalah iklan yang membuat konsumen tertarik memilih es krim Wall's Magnum, dan banyak diminati oleh masyarakat luas karena memiliki berbagai varian rasa dan memiliki simbol tersendiri. Kemasan dan promosi yang dilakukan menunjukan kemewahan atau kesan glamour bagi penikmat atau pengonsumi es krim Wall's Magnum, sehingga membuat konsumen merasa harga dirinya naik atau tingkat gengsinya lebih tinggi dibandingkan mengonsumsi es krim lainnya yang sebanding.

Wall's Magnum memberikan sensasi yang berbeda dengan memberikan kesempatan kepada konsumen untuk memanjakan diri dengan kenikmatan cita rasa spesial secara visual, presepsi dan indrawi. Untuk menciptakan citra merek es krim Wall's Magnum, perusahaan menggunakan bauran promosi untuk merek produknya agar menjadi daya tarik bagi konsumen. Promosi dapat dilakukan dengan beberapa cara seperti advertising (periklanan), public relation, sales promotion dan personal selling.

Tabel 1.

Rata-Rata Penjualan

\begin{tabular}{ccc}
\hline Merek & Top Brand 2016 & Top Brand 2017 \\
\hline Wall's & 70,7 & 71,2 \\
Campina & 15,9 & 14,7 \\
Diamond & 5,4 & 4,5 \\
\hline
\end{tabular}

Sumber: Top Brand Of Ice Cream

Pada Tabel 1, hasil riset yang dilakukan Top Brand Of Ice Cream menjelaskan bahwa pada tahun 2016 es krim merek Wall's berada dalam peringkat pertama, dimana posisi tersebut berada di atas es krim merek Campina dan es krim merek Diamond. Berdasarkan fenomena yang terjadi sekarang yaitu 
banyaknya konsumen yang tertarik untuk membeli produk es krim Wall's, maka penulis melakukan penelitian dengan produk es krim Wall's Magnum sebagai objek pembahasan dalam tugas akhir dengan judul: Peran Citra Merek Memediasi Pengaruh Iklan terhadap Keputusan Pembelian Produk Es krim Wall's Magnum.

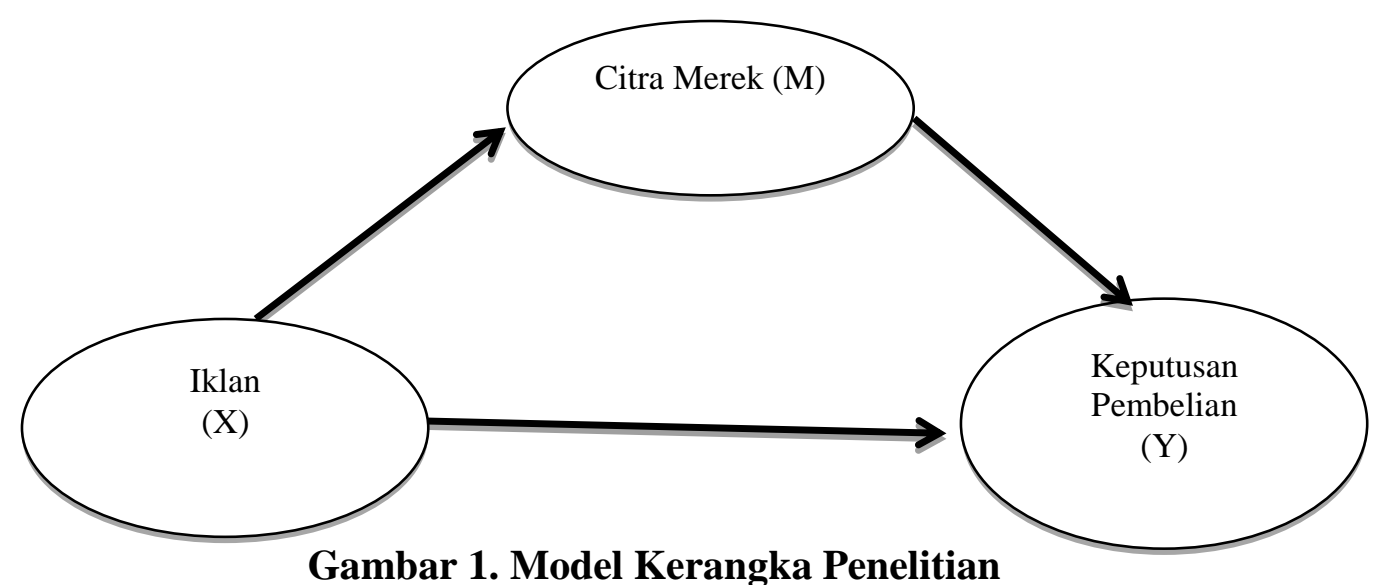

Penelitian Tanoni (2013) mengatakan bahwa iklan berpengaruh positif terhadap citra merek. Iklan adalah faktor yang perlu diperhatikan pihak perusahaan dalam menarik pelanggan, karena iklan yang ditampilkan pada media televisi mampu menarik perhatian konsumen, sehingga meyakinkan konsumen untuk memilih produk tersebut karena konsumen menilai bahwa produk yang di iklan tersebut memiliki citra merek yang baik.

Studi empiris dilakukan oleh Situmorang (2017) yang melakukan penelitian tentang pengaruh kualitas produk dan iklan terhadap citra merek dan keputusan pembelian produk kecantikan merek pond's pada remaja di kota pekan baru menunjukkan hasil bahwa iklan berpengaruh positif dan signifikan terhadap citra merek kosmetik kecantikan merek pond's pada remaja di kota pekan baru. 
$\mathrm{H}_{1}$ : Iklan berpengaruh secara positif terhadap citra merek

Citra merek yang dimiliki perusahaan dapat membantu dalam meningkatkan penjualan suatu produk karena dengan citra merek, konsumen sudah mengenal dan mengetahui tentang produk tersebut. Penelitian sebelumnya yang dilakukan oleh Kiswalini (2014) menunjukkan bahwa brand image memiliki pengaruh yang signifikan terhadap keputusan pembelian, semakin baik citra merek produk maka kecenderungan konsumen dalam melakukan pembelian juga akan meningkat.

Menurut Peter dan Olson (dalam Rangkuti 2009:20-21) bahwa dalam pengambilan keputusan pembelian, jika konsumen dihadapkan pada pilihan seperti nama merek, harga, serta berbagai atribut produk lainnya, ia akan cenderung memilih nama merek terlebih dahulu setelah itu memikirkan harga, ini karena citra merek yang terbentuk di benak konsumen yang terbiasa menggunakan merek tertentu cenderung memiliki konsistensi dalam pembelian produk yang diinginkan. Lebih lanjut menurut Bian (2011) menyebutkan bahwa dimensi brand image yang dihasilkan oleh konsumen memiliki pengaruh terhadap keinginan konsumen untuk membeli dan pada akhirnya menghasilkan keputusan pembelian.

$\mathrm{H}_{2}$ : Citra merek berpengaruh secara positif terhadap keputusan pembelian

Kreatifitas dalam membuat iklan adalah hal yang sangat penting, dimana tidak hanya untuk strategi komunikasi saja tetapi juga sebagai sarana inovasi untuk mengingatkan konsumen akan produk yang tawarkan (Nyilasy, 2013). Iklan yang menarik dan kreatif tentunya akan memiliki dampak positif terhadap suatu merek dan sebaliknya iklan yang kurang menarik tentunya akan berdampak 
negatif terhadap perusahaan.

Berdasarkan penelitian yang dilakukan oleh Rosyid (2013) Pengaruh Kualitas Produk, Citra Merek, Harga dan Iklan Terhadap Keputusan Pembelian Sepeda Motor Honda Revo (Studi Kasus pada Konsumen Sepeda Motor Honda Revo Astra Motor Kebumen) hasilnya adalah iklan berpengaruh positif terhadap keputusan pembelian. Menurut penelitian Dessy, (2014) Pengaruh Iklan Dan Citra Merek Terhadap Keputusan Pembelian Yamaha Mio (Studi pada PT. Yamaha Mataram Sakti di Kota Semarang) hasilnya adalah iklan berpengaruh positif dan signifikan terhadap keputusan pembelian konsumen.

$\mathrm{H}_{3}$ : Iklan berpengaruh secara positif terhadap keputusan pembelian

Citra merek memediasi pengaruh iklan terhadap keputusan pembelian, dengan begitu perusahaan yang telah mepromosikan produknya melalui media iklan akan terdorong untuk memiliki citra merek suatu produk. Citra merek adalah apa yang dipersepsikan oleh konsumen mengenai sebuah merek. Dimana hal ini menyangkut bagaimana seorang konsumen menggambarkan apa yang mereka pikirkan mengenai sebuah merek dan apa yang mereka rasakan mengenai merek tersebut, Sari (2014). Iklan produk yang baik akan menciptakan citra merek yang dapat mempengaruhi keputusan pembelian suatu produk.

$\mathrm{H}_{4}$ : Citra merek memediasi pengaruh iklan terhadap keputusan

\section{METODE PENELITIAN}

Lokasi penelitian ini dilakukan di beberapa mini market yang berada dikawasan kecamatan Kuta,dimana mini market yang terdapat di daerah Kuta tersebut merupakan mini market yang menjual produk es krim Wall's dengan 
berbagai macam varian salah satunya adalah es krim Wall's Magnum. Penelitian ini dilakukan dengan memberikan kuesioner kepada konsumen.

Jenis data menggunakan data kuantitatif merupakan jenis data yang dinyatakan dalam bentuk angka dan memiliki satuan hitung atau jumlah skor dari jawaban kuesioner, serta data kualitatif merupakan data yang tidak dapat dinyatakan kedalam bentuk angka. Data kualitatif yang dikumpulkan adalah data mengenai gambaran umum mengenai es krim Wall's Magnum.

Sumber data menggunakan sumber primer, dalam penelitian ini dikumpulkan melalui hasil wawancara dan jawaban dari kuesioner yang disebarkan pada responden, serta sumber sekunder, yang dikumpulkan dalam penelitian ini yaitu data yang diperoleh dengan mengumpulkan data informasi dari pihak lain.

Pada penelitian ini menggunakan tiga jenis variabel yaitu variabel eksogen adalah variabel yang mempengaruhi atau menjadi penyebab berubahnya variabel endogen atau timbulnya variabel endogen. Variabel eksogen (X), dalam penelitian ini yaitu Iklan. Variabel mediasi adalah variabel yang mempengaruhi variabel eksogen terhadap variabel endogen (Santoso, 2014:9). Variabel mediasi (M), dalam penelitian ini yaitu Citra Merek. Variabel endogen bersifat dipengaruhi oleh variabel endogen. Variabel endogen (Y), dalam penelitian ini yaitu Keputusan Pembelian.

Populasi yang digunakan dalam penelitian ini adalah masyarakat lokal di Kecamatan Kuta yang pernah atau telah mengkonsumsi es krim Wall's Magnum, serta pernah melihat atau mendengar iklan es krim Wall's Magnum, yang jumlah populasinya tidak diketahui (infinite). Dalam penelitian ini metode penentuan 
sampel menggunakan non probability. Teknik penarikan sampel menggunakan teknik purposive sampling.

Instrumen penelitian menggunakan kuesioner dengan menggunakan skala likert dimana variasi skor antara (5) sangat setuju - (1) sangat tidak setuju, untuk mengetahui layak atau tidaknya data digunakan maka perlu melakukan uji validitas dan uji reliabilitas. Kuesioner merupakan daftar pertanyaan terstruktur yang telah dipersiapkan sebelumnya dan diberikan kepada responden yang telah dipilih dan dipergunakan untuk memperoleh data konsumen atau responden. Kuesioner terdiri dari pertanyaan terbuka tentang identitas responden dan pernyataan yang merupakan indikator-indikator dari variabel penelitian. Melalui kuesioner maka akan diperoleh informasi yang relevan dengan tujuan survey dan dapat memperoleh informasi seakurat mungkin.

Teknik analisis data yang digunakan dalam penelitian ini adalah teknik analisis jalur (path analysis). Model path analysis merupakan perluasan dari analisis regresi linier berganda, dimana uji ini digunakan untuk menaksir hubungan kausalitas antar variabel (model causal) yang telah ditetapkan sebelumnya berdasarkan teori (Ghozali, 2007:174). Menurut Ridwan (2011), analisis jalur digunakan untuk menganalisis pola hubungan antar variable dengan tujuan untuk mengetahui pengaruh langsung maupun tidak langsung variabel bebas (eksogen) terhadap variabel terikat (endogen). Dasar perhitungan koefisien jalur adalah analisis regresi dan korelasi, dalam perhitungannya menggunakan software dengan program SPSS for windows. 
Uji sobel digunakan untuk menguji kekuatan pengaruh tidak langsung variabel pengaruh iklan $(\mathrm{X})$ terhadap keputusan pembelian $(\mathrm{Y})$ melalui citra merek (M), dihitung dengan cara mengalihkan koefisien jalur X terhadap M (a) dengan koefisien jalur $\mathrm{M}$ terhadap $\mathrm{Y}(\mathrm{b})$ atau $\mathrm{ab}$. Standar eror koefisien $\mathrm{a}$ atau $\mathrm{b}$ ditulis dengan $\mathrm{Sa}$ dan $\mathrm{Sb}$, besarnya standar eror tidak langsung (Indirect Effect) Sab. Uji sobel dapat dirumuskan ke dalam rumus sebagai berikut:

$$
Z=\frac{a b}{\sqrt{b^{2} s_{a}^{2}+a^{2} s_{b}^{2}+s_{a}^{2} s_{b}^{2}}}
$$

\section{Keterangan:}

a $\quad=$ Koefisien regresi dari variabel X terhadap variabel $\mathrm{M}$.

$S_{a} \quad=$ Standar eror dari a.

$s_{b} \quad=$ Standar eror dari b.

$\mathrm{b} \quad=$ Koefisien regresi dari variabel $\mathrm{M}$ terhadap variabel $\mathrm{Y}$.

Untuk menguji keputusan dalam pengujian hipotesis, maka dilakukan langkah sebagai berikut:

(1) Rumusan Hipotesis

$H_{0}$ : Citra merek tidak memediasi pengaruh iklan terhadap keputusan pembelian es krim Wall's Magnum.

$H_{1}$ : Citra merek memediasi pengaruh iklan terhadap keputusan pembelian es krim Wall's Magnum.

(2) Taraf nyata yang digunakan dalam penelitian ini adalah $5 \%$

(3) Kriteria pengujian (z tabel 1,96) 
$\mathrm{z}$ hitung $\leq \mathrm{z}$ tabel, maka $H_{0}$ diterima yang berarti $\mathrm{M}$ bukan variabel mediasi.

z hitung $>$ z tabel, maka $H_{0}$ ditolak yang berarti $\mathrm{M}$ bukan variabel mediasi.

(4) Menghitung z, hitung mengunakan rumus

(5) Kesimpulan

\section{HASIL DAN PEMBAHASAN}

Tabel 2. menjelaskan karakteristik responden, dimana sampel yang diambil sebesar 100 orang, karakteristik responden ini diukur dari jenis kelamin, usia, pekerjaan atau pendidikan terakhir.

Tabel 2.

\section{Karakteristik Responden}

\begin{tabular}{|c|c|c|c|}
\hline No & Variabel & Klasifikasi & Jumlah (orang) \\
\hline \multirow{3}{*}{1} & \multirow{2}{*}{ Jenis Kelamin } & Laki-Laki & 52 \\
\hline & & Perempuan & 48 \\
\hline & \multicolumn{2}{|c|}{ Jumlah } & 100 \\
\hline \multirow{4}{*}{2} & \multirow{3}{*}{ Usia } & 17-25 Tahun & 74 \\
\hline & & 26-35 Tahun & 25 \\
\hline & & 35 Tahun Keatas & 1 \\
\hline & \multicolumn{2}{|c|}{ Jumlah } & 100 \\
\hline \multirow{6}{*}{3} & \multirow{5}{*}{$\begin{array}{c}\text { Pekerjaan atau Pendidikan } \\
\text { Terakhir }\end{array}$} & Siswa/i & 24 \\
\hline & & Mahasiswa/i & 45 \\
\hline & & Pegawai Swasta & 4 \\
\hline & & Wiraswasta & 13 \\
\hline & & Lain-Lain & 4 \\
\hline & \multicolumn{2}{|c|}{ Jumlah } & 100 \\
\hline
\end{tabular}

Sumber: Data primer diolah, 2017

Tabel 2 menunjukan karakteristik responden dapat dilihat berdasarkan pengelompokkan jenis kelamin, jenis kelamin laki-laki mendominasi dalam penelitian ini, berdasarkan usia responden yang memiliki usia 17-25 Tahun 
mendominasi dalam penelitian ini, dan berdasarkan pekerjaan atau pendidikan terakhir yang mendominasi adalah mahasiswa/i dalam penelitian ini.

Pengujian validitas adalah menguji sejauh mana intrumen yang digunakan dalam penelitian ini mampu mengukur variabel yang telah di tetapkan oleh peneliti. Suatu instrumen yang valid ditunjukkan dengan r Pearson Correlation skor total $\geq 0,30$ pada Tabel 3 .

Tabel 3.

Hasil Uji Validitas Instrumen

\begin{tabular}{|c|c|c|c|c|}
\hline No & Variabel & Instrumen & Pearson Correlation & Keterangan \\
\hline \multirow{4}{*}{1.} & \multirow{4}{*}{ Iklan $(\mathrm{X})$} & X.1 & 0,843 & Valid \\
\hline & & X.2 & 0,844 & Valid \\
\hline & & X.3 & 0,825 & Valid \\
\hline & & X.4 & 0,806 & Valid \\
\hline \multirow{3}{*}{2.} & \multirow{3}{*}{ Citra Merek (M) } & M.1 & 0,816 & Valid \\
\hline & & M.2 & 0,754 & Valid \\
\hline & & M.3 & 0,786 & Valid \\
\hline \multirow{3}{*}{3.} & \multirow{3}{*}{$\begin{array}{c}\text { Keputusan } \\
\text { Pembelian (Y) }\end{array}$} & Y.1 & 0,910 & Valid \\
\hline & & Y.2 & 0,808 & Valid \\
\hline & & Y.3 & 0,923 & Valid \\
\hline
\end{tabular}

Sumber: Data primer diolah, 2017

Tabel 3, variabel penelitian berupa iklan, citra merek dan keputusan pembeliantelah memenuhi syarat uji validitas yang dimana nilai skor total Pearson Correlation masing-masing instrumen berada diatas 0,30 dan mimiliki nilai signifikansi yang lebih kecil dari 5\% (0,05), maka instrumen layak digunakan menjadi alat ukur variabel-variabel tersebut.

Pengujian reliabilitas adalah suatu pengujian pada instrumen penelitian demi mendapatkan hasil bahwa instrumen yang digunakan dapat dipercaya dan diandalkan. Pengujian ini, nilai suatu reliabilitas ditunjukkan melalui skor Cronbach's Alpha yang dimana jika nilai skor tersebut berada diatas 0,60 maka 
instrumen tersebut dapat dikatakan reliabel. Hasil penelitian uji reliabilitas dapat dilihat pada Tabel 4.

Tabel 4.

Uji Reliabilitas Instrumen

\begin{tabular}{cccc}
\hline No. & Variabel & Cronbach's Alpha & Keterangan \\
\hline 1. & Iklan $(\mathrm{X})$ & 0,846 & Reliabel \\
2. & Citra Merek $(\mathrm{M})$ & 0,683 & Reliabel \\
3. & Keputusan pembelian $(\mathrm{Y})$ & 0,852 & Reliabel
\end{tabular}

Sumber: Data primer diolah, 2017

Tabel 4 uji reliabilitas pada masing-masing variabel berada pada titik diatas 0,60 yang ditunjukkan pada hasil Cronbach's Alpha, maka dapat dikatakan seluruh instrumen telah memenuhi syarat reliabilitas.

Analisis deskriptif dilakukan untuk mengetahui karakteristik dan tanggapan responden terhadap masing-masing pertanyaan yang diajukan. Penilaian distribusi data setiap variabel menggunakan rentang kriteria yang dihitung dengan rumus:

$$
\begin{aligned}
\text { Nilai Interval } & =\frac{(\text { Nilai batas tertinggi }- \text { nilai batas terendah) }}{\text { Total nilai yang digunakan }} \\
& =\frac{(5-1)}{5} \\
& =0,8
\end{aligned}
$$

Berdasarkan hasil interval range maka dapat disusun kriteria hasil pengukuran penilaian responden sebagai berikut:

$$
\begin{aligned}
& 1,00-1,79=\text { sangat tidak baik } \\
& 1,80-2,59=\text { tidak baik } \\
& 2,60-3,39=\text { cukup } \\
& 3,40-4,19=\text { baik } \\
& 4,20-5,00=\text { sangat baik }
\end{aligned}
$$

Iklan dalam penelitian ini terdiri dari empat indikator. Hasil deskriptif mengenai penilaian responden terhadap iklan ditunjukkan dalam Tabel 5. 
Tabel 5.

Deskripsi Penilaian Responden Terhadap Iklan

\begin{tabular}{|c|c|c|c|c|c|c|c|}
\hline \multirow{2}{*}{ Indikator } & \multicolumn{5}{|c|}{ Skor Jawaban } & \multirow{2}{*}{$\begin{array}{l}\text { Rata- } \\
\text { Rata }\end{array}$} & \multirow{2}{*}{ Kriteria } \\
\hline & 1 & 2 & 3 & 4 & 5 & & \\
\hline $\begin{array}{l}\text { Iklan es krim Wall's Magnum ada di } \\
\text { setiap media (x1) }\end{array}$ & 1 & 1 & 14 & 44 & 40 & 4,21 & $\begin{array}{c}\text { Sangat } \\
\text { Baik }\end{array}$ \\
\hline $\begin{array}{l}\text { Saya mengerti dengan pesan yang } \\
\text { disampaikan oleh iklan es krim } \\
\text { Wall's Magnum (x2) }\end{array}$ & 0 & 4 & 17 & 34 & 45 & 4,20 & $\begin{array}{l}\text { Sangat } \\
\text { Baik }\end{array}$ \\
\hline $\begin{array}{l}\text { Iklan es krim Wall's Magnum } \\
\text { berbeda dengan iklan es krim lainnya } \\
\text { (x3) }\end{array}$ & 1 & 2 & 12 & 30 & 55 & 4.36 & $\begin{array}{l}\text { Sangat } \\
\text { Baik }\end{array}$ \\
\hline $\begin{array}{l}\text { Iklan es krim Wall's Magnum } \\
\text { menarik perhatian anda untuk } \\
\text { membeli (x4) }\end{array}$ & 1 & 2 & 11 & 24 & 62 & 4,44 & $\begin{array}{c}\text { Sangat } \\
\text { Baik }\end{array}$ \\
\hline \multicolumn{6}{|c|}{ Rata-Rata Penilaian Variabel Iklan (X) } & 4,30 & $\begin{array}{c}\text { Sangat } \\
\text { Baik }\end{array}$ \\
\hline
\end{tabular}

Sumber: Data primer diolah, 2017

Tabel 5 hasil penelitian menunjukkan bahwa Iklan secara keseluruhan dinilai oleh responden yang didasarkan pada persepsi rata-rata sebesar 4,30, yang berarti memiliki kriteria sangat baik. Hal ini menunjukkan bahwa penilaian responden terhadap iklan pada es krim Wall's Magnum mengenai masing-masing indikator tersebut sangat baik.

Berdasarkan 4 indikator yang digunakan untuk mengukur Iklan, indikator yang memiliki nilai rata-rata paling tinggi berada di atas nilai rata-rata $(4,30)$ dari keseluruhan indikator iklan yaitu iklan es krim Wall's Magnum menarik perhatian anda untuk membeli (x4) dengan nilai rata-rata 4,44.

Citra merek dalam penelitian ini terdiri dari tiga indikator. Hasil deskriptif mengenai penilaian responden terhadap citra merek ditunjukkan dalam Tabel 6. 
Tabel 6.

Deskripsi Penilaian Responden Terhadap Citra Merek

\begin{tabular}{|c|c|c|c|c|c|c|c|}
\hline \multirow{2}{*}{ Indikator } & \multicolumn{5}{|c|}{ Skor Jawaban } & \multirow{2}{*}{$\begin{array}{l}\text { Rata- } \\
\text { Rata }\end{array}$} & \multirow{2}{*}{ Kriteria } \\
\hline & 1 & 2 & 3 & 4 & 5 & & \\
\hline $\begin{array}{l}\text { Merek Wall's Magnum sudah dikenal } \\
\text { banyak orang (m1) }\end{array}$ & 1 & 1 & 9 & 33 & 56 & 4,42 & $\begin{array}{c}\text { Sangat } \\
\text { Baik }\end{array}$ \\
\hline $\begin{array}{l}\text { Es krim Wall's Magnum memiliki kualitas } \\
\text { yang berbeda dengan es krim lainnya (m2) }\end{array}$ & 1 & 0 & 16 & 33 & 50 & 4,31 & $\begin{array}{c}\text { Sangat } \\
\text { Baik }\end{array}$ \\
\hline $\begin{array}{l}\text { Es krim Wall's Magnum memiliki harga } \\
\text { yang terjangkau(m3) }\end{array}$ & 0 & 2 & 18 & 26 & 54 & 4,32 & $\begin{array}{c}\text { Sangat } \\
\text { Baik }\end{array}$ \\
\hline Rata-Rata Penilaian Variabe & & & & & & 4,35 & $\begin{array}{l}\text { Sangat } \\
\text { Tinggi }\end{array}$ \\
\hline
\end{tabular}

Sumber: Data primer diolah, 2017

Tabel 6 hasil penelitian menunjukkan bahwa citra merek secara keseluruhan dinilai oleh responden yang didasarkan pada persepsi rata-rata sebesar 4,35, yang berarti memiliki kriteria sangat baik. Hal ini menunjukkan bahwa penilaian responden terhadap citra merekpada es krim Wall's Magnum mengenai masingmasing indikator tersebut sangat baik.

Berdasarkan 3 indikator yang digunakan untuk mengukur citra merek, indikator yang nilainya paling tinggi berada di atas nilai rata-rata $(4,35)$ dari keseluruhan indikator citra merek yaitu merek Wall's Magnum sudah dikenal banyak orang (m1)dengan nilai rata-rata 4,42.

Keputusan pembelian dalam penelitian ini terdiri dari tiga indikator. Hasil deskriptif mengenai penilaian responden terhadap keputusan pembelian ditunjukkan dalam Tabel 7. 
Tabel 7.

Deskripsi Penilaian Responden Terhadap Keputusan Pembelian

\begin{tabular}{|c|c|c|c|c|c|c|c|}
\hline \multirow{2}{*}{ Indikator } & \multicolumn{5}{|c|}{ Skor Jawaban } & \multirow{2}{*}{$\begin{array}{l}\text { Rata- } \\
\text { Rata }\end{array}$} & \multirow{2}{*}{ Kriteria } \\
\hline & 1 & 2 & 3 & 4 & 5 & & \\
\hline $\begin{array}{l}\text { Saya memiliki ketertarikan untuk } \\
\text { membeli kembali es krim Wall's } \\
\text { Magnum (y1) }\end{array}$ & 0 & 2 & 15 & 29 & 54 & 4,35 & $\begin{array}{c}\text { Sangat } \\
\text { Baik }\end{array}$ \\
\hline $\begin{array}{l}\text { Saya menganggap es krim Wall's } \\
\text { Magnum memiliki keunggulan } \\
\text { dibanding dengan merek-merek es } \\
\text { krim lainnya (y2) }\end{array}$ & 0 & 0 & 11 & 45 & 44 & 4,33 & $\begin{array}{c}\text { Sangat } \\
\text { Baik }\end{array}$ \\
\hline $\begin{array}{l}\text { Saya akan merekomendasikan es krim } \\
\text { Wall's Magnum kepada orang lain } \\
\text { (y3) }\end{array}$ & 0 & 1 & 16 & 14 & 69 & 4,51 & $\begin{array}{l}\text { Sangat } \\
\text { Tinggi }\end{array}$ \\
\hline \multicolumn{6}{|c|}{ Rata-Rata PenilaianVariabel Keputusan Pembelian (Y) } & 4,40 & $\begin{array}{c}\text { Sangat } \\
\text { Baik }\end{array}$ \\
\hline
\end{tabular}

Tabel 7 hasil penelitian menunjukkan keputusan pembelian secara keseluruhan dinilai oleh responden yang didasarkan pada persepsi rata-rata sebesar 4,40, yang berarti memiliki kriteria sangat baik. Hal ini menunjukkan bahwa penilaian responden mengenai masing-masing indikator tersebut sangat baik.

Berdasarkan 3 indikator yang digunakan untuk mengukur keputusan pembelian, indikator yang nilainya paling tinggi berada di atas nilai rata-rata $(4,40)$ dari keseluruhan indikator keputusan pembelian yaitu konsumen akan merekomendasikan es krim Wall's Magnum kepada orang lain (y3) dengan nilai rata-rata 4,51 .

Tabel 8.

KMO and Bartlett's Test Variabel Iklan

\begin{tabular}{lrr}
\hline \multicolumn{2}{l}{ Kaiser-Meyer-Olkin Measure of Sampling } \\
Adequacy & \\
Bartlett's Test of & Approx. Chi-Square & .824 \\
Sphericity & Df & 169.762 \\
& Sig. & 6 \\
Sumber: Data primer diolah, 2017
\end{tabular}


Tabel 8 hasil perhitungan analisis faktor konfirmatori pada konsumen produk es krim Wall's Magnum didapat nilai KMO pada variabel iklan sebesar 0,824 .

Tabel 9. KMO and Bartlett's Test Variabel Citra Merek Kaiser-Meyer-Olkin Measure of Sampling Adequacy Bartlett's Test of Approx. Chi-Square Sphericity Df 89.328

Sig.

Sumber: Data primer diolah, 2017

Tabel 9 hasil perhitungan analisis faktor konfirmatori pada konsumen produk es krim Wall's Magnum didapat nilai KMO pada variabel citra merek sebesar 0,699.

Tabel 10.

KMO and Bartlett's Test Variabel Keputusan Pembelian

Kaiser-Meyer-Olkin Measure of Sampling

Adequacy

Bartlett's Test of

Approx. Chi-Square

128.198

Sphericity

Df

3

Sumber: Data primer diolah, 2017

Tabel 10 hasil perhitungan analisis faktor konfirmatori pada konsumen produk es krim Wall's Magnum didapat nilai KMO pada variabel keputusan pembelian sebesar 0,694 .

Pada penelitian ini digunakan teknik path analysis untuk melihat pengaruh hubungan masing-masing variabel eksogen yang terdiri dari iklan, variabel endogen yang terdiri dari citra merek dankeputusan pembelian. Penelitian ini juga menguji peran variabel intervening yaitu citra merekdalam memediasi hubungan antara variabel pengaruh iklan terhadap keputusan pembelian. Berikut ini ditampilkan hasil perhitungan struktur pertama pada Tabel 11. 
Tabel 11.

Hasil Analisis Jalur Pengaruh Iklan Terhadap Citra Merek

\begin{tabular}{|c|c|c|c|c|c|c|}
\hline & \multirow[t]{2}{*}{ Model } & \multicolumn{2}{|c|}{$\begin{array}{l}\text { Unstandardized } \\
\text { Coefficients }\end{array}$} & \multirow{2}{*}{$\begin{array}{c}\text { Standardized } \\
\text { Coefficients } \\
\text { Beta }\end{array}$} & \multirow{2}{*}{$\mathbf{t}$} & \multirow{2}{*}{ Sig. } \\
\hline & & B & Std. Error & & & \\
\hline \multirow[t]{2}{*}{1} & (Constant) & 1,498 & 0,501 & & 2,993 & 0,003 \\
\hline & Iklan & 0,671 & $\mathbf{0 , 0 2 9}$ & 0,921 & 23,378 & 0,000 \\
\hline
\end{tabular}

Sumber: Data primer diolah, 2017

Tabel 11 maka dapat dirumuskan persamaan struktural yang terbentuk adalah sebagai berikut:

$$
\begin{aligned}
& M=\beta_{1} X+e_{1} \\
& M=0,671 X+e 1
\end{aligned}
$$

Persamaan struktural tersebut dapat diartikan yaitu:

Variabel iklan sebesar (+) 0,671 berartiiklanmempunyai pengaruh positif terhadap citra merek, ini diartikan apabila iklan meningkat maka citra merekakan meningkat sebesar 0,671 .

Pada penelitian ini dihitung pengaruh iklan dan citra merek terhadap keputusan pembelianmelalui program SPSS for windows. Berikut ini ditampilkan hasil perhitungan struktur kedua pada Tabel 12.

Tabel 12.

Hasil Analisis Jalur Pengaruh Iklan dan Citra Merek Terhadap Keputusan Pembelian

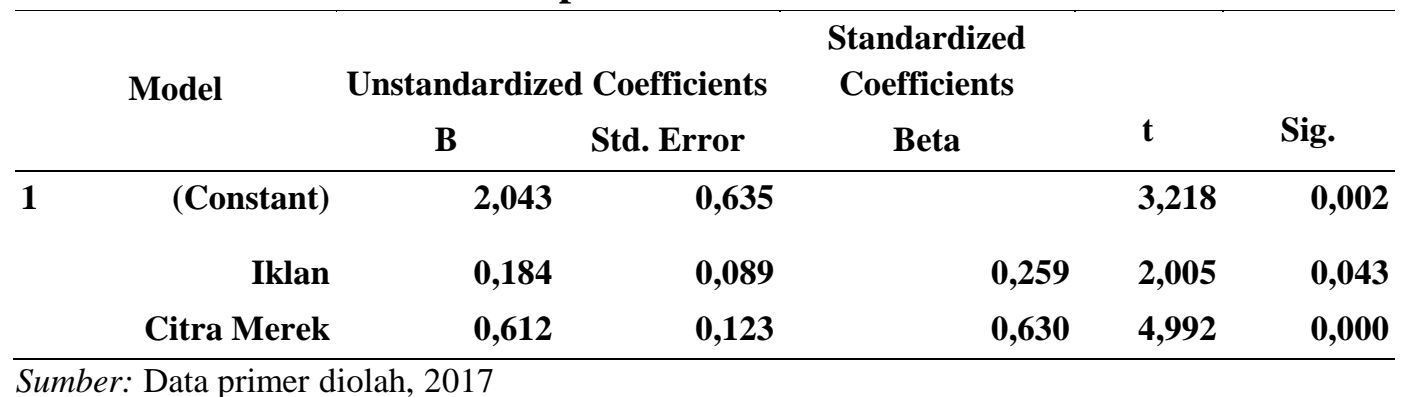


Tabel 12 maka dapat dirumuskan persamaan struktural yang terbentuk adalah sebagai berikut:

$$
\begin{aligned}
& Y=\beta_{1} X+\beta_{2} M+e_{2} \\
& Y=0,184 X+0,612 M+e_{2}
\end{aligned}
$$

Persamaan struktural tersebut dapat diartikan yaitu:

1) Variabel iklan memiliki koefisien sebesar (+) 0,184 berarti iklan memiliki pengaruh positif terhadap keputusan pembelian, ini diartikan apabila iklan meningkat maka keputusan pembelian akan meningkat sebesar 0,184 .

2) Variabel citra merek memiliki koefisien sebesar (+) 0,612 berarti citra merek memiliki pengaruh positif terhadap keputusan pembelian, ini diartikan apabila citra merek meningkat maka keputusan pembelian akan meningkat sebesar 0,612.

Perhitungan dari nilai standar eror berdasarkan model hasil analisis jalur 1 dan hasil analisis jalur 2 adalah sebagai berikut:

$$
\begin{aligned}
& \mathrm{e}_{\mathrm{i}}=\sqrt{1-\mathrm{Ri}^{2}} \\
& \mathrm{e}_{1}=\sqrt{1-\mathrm{Ri}^{2}}=\sqrt{1-0,848}=\sqrt{0,152}=0,389 \\
& \mathrm{e}_{2}=\sqrt{1-\mathrm{Ri}^{2}}=\sqrt{1-0,765}=\sqrt{0,235}=0,484
\end{aligned}
$$

Berdasarkan perhitungan diatas mengenai persamaan struktur, perhitungan error dan determinasi total serta pengaruh variabel maka dapat disimpulkanbahwa melalui diagram jalur peran citra merek dalam memediasi iklanterhadap 
keputusan pembelian pada hipotesis penelitian ini dapat digambarkan pada Gambar 2. berikut ini:

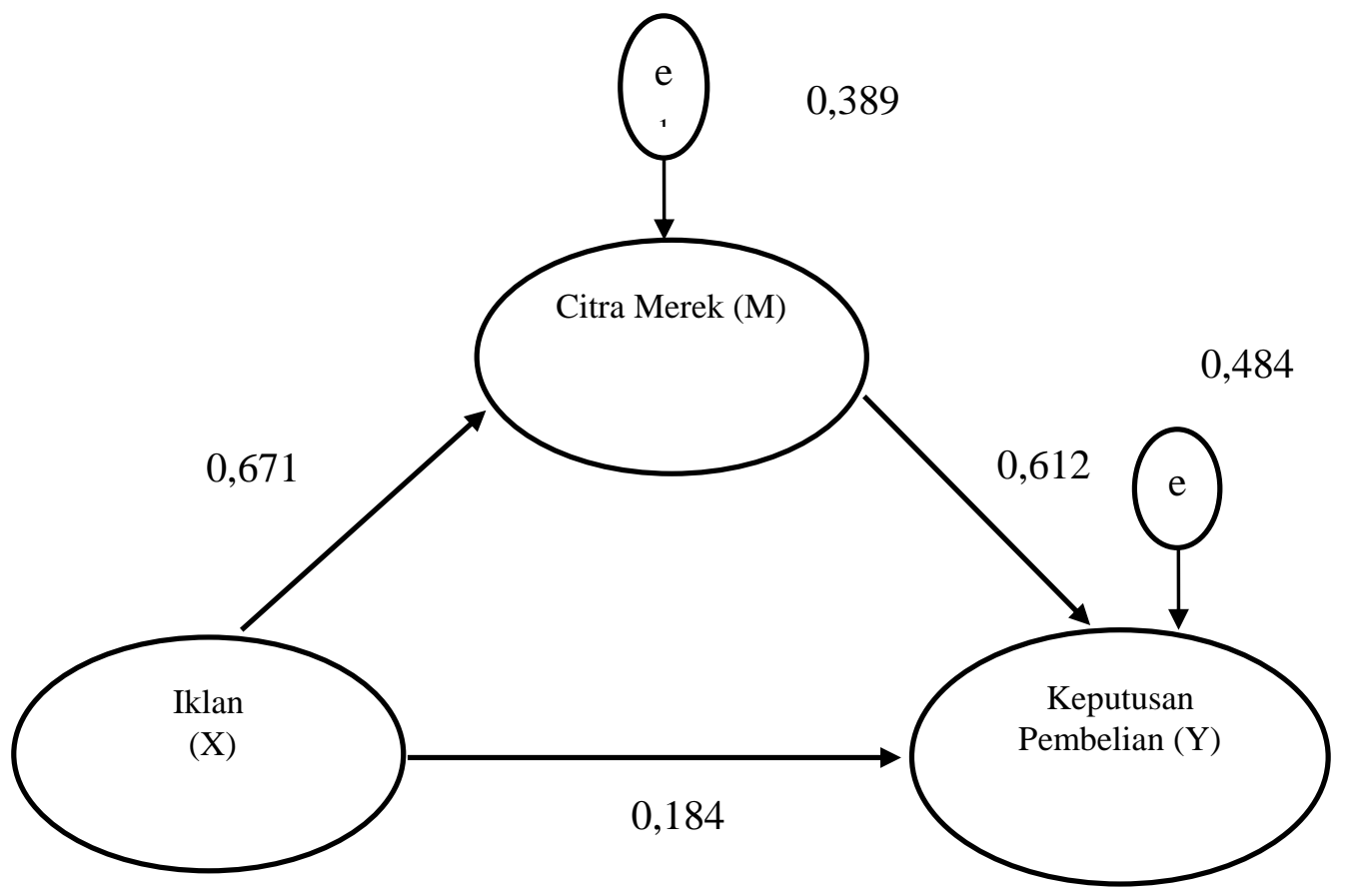

Sumber: Data Primer diolah, 2017.

Uji normalitas menggunakan uji Kolmogorov-Smirnov, dengan uji ini dapat diketahui data yang digunakan berdistribusi normal atau tidak. Apabila Sign t hitung $>0.05$, maka data tersebut berdistribusi normal dan begitu juga sebaliknya.

Tabel 13.

Hasil Uji Normalitas Struktur 1 dan Struktur 2

\begin{tabular}{llrr}
\hline & & $\begin{array}{c}\text { Unstandardized } \\
\text { Residual }\end{array}$ & $\begin{array}{c}\text { Unstandardized } \\
\text { Residual }\end{array}$ \\
\hline $\mathrm{N}$ & & 100 & 100 \\
Normal Parameters & Mean & .0000000 & .0000000 \\
& Std. Deviation & .79812079 & .96370877 \\
Most Extreme Differences & Absolute & .126 & .133 \\
& Positive & .108 & .133 \\
& Negative & -.126 & -.109 \\
Kolmogorov-Smirnov Z & & 1.263 & 1.326 \\
Asymp. Sig. (2-tailed) & & .082 & .059 \\
\hline Sumber: Data primer diolah, 2017 & &
\end{tabular}


Tabel 13 menunjukkan bahwa nilai signifikansi sebesar 0,082 dan 0,059> $\alpha$ $=0,05$ maka dapat disimpulkan bahwa data terdistribusi secara normal.

Uji multikolinieritas digunakan untuk mengetahui apakah antara variabel bebas terjadi multikolinieritas atau tidak. Uji yang digunakan yaitu dengan melihat nilai VIF (Varian Inflation Factor) dan Tolerance pada proses regresi biasa, jika keduanya mendekati 1 atau besaran VIF kurang dari 10 maka model tidak terkena multikolonieritas.

Tabel 14.

Hasil Uji Multikolinieritas

\begin{tabular}{|c|c|c|c|}
\hline No & Variabel & Nilai Tolerance & Nilai VIF \\
\hline 1 & Iklan & 0,152 & 6,577 \\
\hline 2 & Citra Merek & 0,152 & 6,577 \\
\hline
\end{tabular}

Sumber: Data primer diolah, 2017

Tabel 14 menunjukan bahwa nilai tolerance Iklan dan Citra Merek> 0,1 dan nilai VIF <10. Jadi dapat disimpulkan bahwa tidak terdapat gejala multikolinearitas.

Uji heteroskedastisitas bertujuan untuk menguji apakah dalam model terjadi ketidaksamaan varian atau residual satu pengamatan ke pengamatan lainnya.Model yang dapat digunakan untuk menguji dengan gejala glejser. Jika tingkat signifikan lebih besar dari 0,05 maka terjadi heteroskedastisitas (Santoso, 2001).

Tabel 15.

Hasil Uji Heteroskedastisitas Struktur 1

\begin{tabular}{cccc}
\hline No & Variabel & Sig. & Keterangan \\
\hline 1 & Iklan & 0,061 & Bebas Heteroskedastisitas \\
\hline Sumber: & Data primer diolah, 2017 & &
\end{tabular}


Tabel 15 memperlihatkan tingkat signifikansi variabelIklanyaitu 0,061 > 0,05 sehingga dapat disimpulkan bahwa model terbebas dari gejala heteroskedastisitas.

Tabel 16.

Hasil Uji Heteroskedastisitas Struktur 2

\begin{tabular}{clcc}
\hline No & \multicolumn{1}{c}{ Variabel } & Sig. & Keterangan \\
\hline 1 & Iklan & 0,112 & Bebas Heteroskedastisitas \\
2 & Citra Merek & 0,379 & Bebas Heteroskedastisitas \\
\hline Sumber: & Data primer diolah, 2017 & &
\end{tabular}

Tabel 16 memperlihatkan tingkat signifikansi tiap variabel > 0,05 sehingga dapat disimpulkan bahwa model terbebas dari gejala heteroskedastisitas.

Berdasarkan hasil pada Tabel 11 nilai iklan sebesar 0,671 dan nilai Sig. sebesar 0,000, maka $\mathrm{H}_{1}$ diterima karena nilai Sig. 0,000<0,05. Kesimpulannya, iklan mempunyai pengaruh positif terhadap citra merek dengan kata lain semakin baik iklan maka citra merek konsumen es krim Wall's Magnum akan semakin meningkat. Sehingga hipotesis pertama diterima.

Berdasarkan hasil pada tabel 12 nilai citra merek sebesar 0,612 dan nilai Sig. sebesar 0,000, maka $\mathrm{H}_{2}$ diterima karena nilai Sig. $0.000<0,05$. Kesimpulannya, citra merek mempunyai pengaruh positif terhadap keputusan pembelian, dengan kata lain apabila citra merek meningkat maka keputusan pembelian konsumen es krim Wall's Magnum akan semakin meningkat. Sehingga hipotesis kedua diterima.

Berdasarkan hasil pada tabel 13 nilai iklan sebesar 0,184 dan nilai Sig. sebesar 0,043, maka $\mathrm{H}_{3}$ diterima karena nilai Sig. 0,043 < 0,05. Kesimpulannya, iklan mempunyai pengaruh positif terhadap keputusan pembelian, dengan kata 
lain semakin meningkat iklan produk, maka semakin meningkat tingkat keputusan pembelian konsumen. Sehingga hipotesis ketiga diterima.

Untuk menguji keputusan dalam pengujian hipotesis, maka dilakukan langkah sebagai berikut:

(1) Rumusan Hipotesis

$H_{0}$ : Citra merek tidak memediasi pengaruh iklan terhadap keputusan pembelian es krim Wall's Magnum.

$H_{1}:$ Citra merek memediasi pengaruh iklan terhadap keputusan pembelian es krim Wall's Magnum.

(2) Taraf nyata yang digunakan dalam penelitian ini adalah $5 \%$

(3) Kriteria pengujian (z tabel 1,96)

$\mathrm{z}$ hitung $\leq \mathrm{z}$ tabel, maka $H_{0}$ diterima yang berarti $\mathrm{M}$ bukan variabel mediasi.

$\mathrm{z}$ hitung $>\mathrm{z}$ tabel, maka $H_{0}$ ditolak, yang berarti $\mathrm{M}$ merupakan variabel mediasi.

(4) Menghitung z, hitung mengunakan rumus

$$
Z=\frac{a b}{\sqrt{b^{2} s_{a}^{2}+a^{2} s_{b}^{2}+s_{a}^{2} s_{b}^{2}}}
$$

Keterangan:

$$
\begin{array}{ll}
\text { a } & =0,921 \\
S_{a} & =0,029 \\
S_{b} & =0,63
\end{array}
$$




$$
\begin{aligned}
& Z=\frac{\mathrm{b}}{\sqrt{\left(0,63^{2}\right)\left(0,029^{2}\right)+\left(0,921^{2}\right)\left(0,123^{2}\right)+\left(0,029^{2}\right)\left(0,123^{2}\right)}} \\
& Z=\frac{0,123}{\sqrt{(0,3969)(0,0008)+(0,8482)(0,0151)+(0,0008)(0,123)}} \\
& Z=\frac{0,5802}{\sqrt{0,0003+0,0128+0,0000}} \\
& Z=\frac{0,5802}{0,114802} \\
& Z=5,0542 \\
& \text { (5) Kesimpulan } \\
& \text { Berdasarkan hasil Uji Sobel menunjukkan bahwa hasil kalkulasi } Z= \\
& \text { 5,0542 }>1,96 \text { dengan tingkat signifikansi 0,000 yang lebih kecil dari } \\
& \text { terhadap keputusan pembelian. Sehingga hipotesis keempat diterima. }
\end{aligned}
$$

\section{SIMPULAN DAN SARAN}

Berdasarkan penelitian yang telah dilakukan maka dapat disimpulkan bahwa: 1) Iklan berpengaruh secara positif terhadap citra merek. Hasil ini menyimpulkan bahwa semakin menarik iklan, maka semakin tinggi citra merek produk. 2) Citra merek berpengaruh secara positif terhadap keputusan pembelian. Hasil penelitian menyimpulkan bahwa semakin tinggi citra merek semakin tinggi keputusan pembelian. 3) Iklan berpengaruh secara positif terhadap keputusan pembelian. Hasil ini menyimpulkan bahwa semakin menarik iklan, maka keputusan pembelian akan semakin tinggi. 4) Citra merek memediasi pengaruh 
iklan terhadap keputusan pembelian. Hasil ini menyimpulkan bahwa citra merek mampu memediasi pengaruh iklan dengan keputusan pembelian.

Berdasarkan penelitian ini, maka saran yang dapat diberikan sebagai berikut: 1) Pihak es krim Wall's Magnum sebaiknya memerhatikan iklan dari segi tampilan maupun dari segi isi dimana dari iklan tersebut konsumen mengerti dengan pesan yang disampaikan melalui iklan. 2) Sebaiknya pihak es krim Wall's Magnum memerhatikan citra merek dari segi kualitas, sehingga dapat memberikan kesan positif bagi konsumen. 3) Pihak es krim Wall's Magnum harus lebih memerhatikan citra merek produk yang terdapat dalam iklan syang nantinya berpengaruh terhadap keputusan pembelian konsumen. 4) Diharapkan kepada peneliti berikutnya untuk meneliti variabel lainnya yang mempunyai pengaruh terhadap keputusan pembelian, sehingga mampu menganalisis secara lebih lanjut faktor-faktor yang dapat mempengaruhi keputusan pembelian.

\section{REFERENSI}

Apriyani, Y. 2013. Pengaruh Brand Image, Harga Dan Kualitas Pelayanan Terhadap Keputusan Pembelian Ulang Pizza Hut di Kota Padang. Jurnal Manajemen, 2(1), pp: 1-10.

Arslan, Muhammad \& Phil, M. 2014. Impact of Brand Image and Service Quality on Consumer Purchase Intention: A Study of Retail Store in Pakistan. Journal Research on Humanities and Social Sciences. Vol. 4, No.22.

Bian, Xuemei., Luiz Moutinho. 2011. The Role of Brand Image, Product Involvement, and Knowledge in Explaining Consumer Purchase Behavior of Counterfeits, European Journal of Marketing. Vol. 45, pp: 191-215.

Dessy, A. Sembiring., Hari Susanta., Bulan Prabawani. 2014. Pengaruh Iklan Dan Citra Merek Terhadap Keputusan Pembelian Yamaha Mio (Studi pada PT. Yamaha Mataram Sakti di Kota Semarang). Jurnal Ekonomi Manajemen. Vol. 3 No. 4.

Dewi, Ni Luh Gede Diah Nirmala, dan Made Jatra. 2013. Pengaruh Atribut Produk Terhadap Keputusan Pembelian Handphone Di Kota Denpasar. E- 
Jurnal Manajemen Universitas Udayana, 3(6), h: 248-261.

Dharmmesta, Basu Swasta dan T. Hani Handoko. 2012. Manajemen Pemasaran: Analisis Perilaku Konsumen. Edisi Pertama. Yogyakarta: BPFEYogyakarta.

Fatlahah, Aniek. 2013. Pengaruh Kualitas Produk Dan Citra Merek Terhadap Keputusan Pembelian Es krim Wall's Magnum. Jurnal Ilmu Manajemen Vol 1, No 2, hal: 472-484.

Gholami Saeed, Ebrahim Roushanghias., and Mahdi Karimiankakolaki. 2016. Examination of factors Influencing on Enhancement of Brand Equity with Emphasis on Advertising and Sales Promotion. Journal of Current Research in Science, 1(2): 320-326.

Ghozali, Imam. 2011. Aplilasi Analisis Multivariate dengan Program IBM SPSS 19. Semarang: Badan Penerbit UNDIP.

Ghozali, Imam. 2007. Aplikasi Analisis Multivariate bagi Program SPSS. Badan Penerbit UNDIP. Semarang.

Goenawan, Kevin. 2014. Pengaruh produk attributes, brand name, product price, dan social influence terhadap purchase intention Android Smartphone di Surabaya. Jurnal Ilmiah Ekonomi. 3(1): h: 1-17.

Hariadi, Doni. 2013. Pengaruh Produk, Harga, Promosi, dan Distribusi Terhadap Keputusan Pembelian Konsumen Pada Produk Microvision. Jurnal Ilmu dan Riset Manajemen, 1 (1): 67-87.

Khasanah dan Pamujo. 2011. Analisis Pengaruh Atribut Produk, Bauran Promosi, Dan Kualitas Pelayanan Terhadap Keputusan Pembelian Produk Merchandise. Jurnal Manajemen. Vol. 13, No. 1, Hal. 156-163.

Kiswalinni, Annis. 2014. Pengaruh Celebrity Endorser, Brand Image, Dan Kepercayaan Konsumen Terhadap Keputusan Pembelian. E-Jurnal Manajemen Universitas Udayana, 3(6), H: 1522-1534.

Kotler, Philip dan Keller, Kelvin. 2007. Manajemen Pemasaran. Jilid 2. Jakarta: Indeks.

Kotler, Philip and Armstrong. 2010. Principles of Marketing 13th edition. New Jersey: Pearson Education Inc.

Kotler, Philip and Kevin Lane Keller. 2012. Marketing Management. New Jersey: Pearson Global Edition.

Kotler, P., \& Keller, K. L. (2012). Marketing Management (14th ed.). New 
Jersey, US: Pearson Education, Inc. Lamb. (2009). Essentials of marketing (6th ed). Mason, US: South-Western Cengage Learning.

Kotler, Philip and Kevin Lane Keller. 2016. Marketing Managemen (Global Edition). Edisi 15e. England: Pearson.

Kurniawan, Denny dan Yohanes Sondang Kunto. 2013. Pengaruh Promosi dan Store Atmosphere terhadap Impulse Buying dengan Shopping Emotion sebagai Variabel Intervening Studi Kasus di Matahari Department Store Cabang SuperMall Surabaya. Jurnal Manajemen Pemasaran Petra, 1(2) h: $1-8$.

Kusumaningtyas, Fitria., et al. 2014 Pengaruh Pesan Iklan Di Televisi Terhadap Keputusan Pembelian (Survei Pada Mahasiswa Jurusan Administrasi Bisnis Fakultas Ilmu Administrasi Universitas Brawijaya Angkatan 2010/2011 Yang Mengkonsumsi Es Krim Magnum) Jurnal Administrasi Bisnis Vol. 13 No. 2, h: 759-765.

Mariyanti, Luh Dwi dan Rahanatha, Gede Bayu. 2015. Pengaruh Celebrity Endorsers Dan Pesan Iklan Di Televisi Terhadap Keputusan Pembelian Pada Es Krim Walls Magnum Belgium Chocolate. E-Jurnal Manajemen Unud, Vol. 4, No. 10, hal: 3093-3118.

Musay, F. P. 2013. Pengaruh Brand Image Terhadap Keputusan Pembelian. Jurnal Aministrasi Bisnis, 3(2), pp: 1-7.

Nyilasy, Gergely., Canniford, Robin., Kreshel, Peggy J. 2013. Ad agency professiona ls mental models of advertising creativity. European Journal of Marketing, 47(10): 1691-1710.

Peter, Paul J. dan Jerry C. Olson. 2013. Perilaku Konsumen dan Strategi Pemasaran. Jilid 1 Ed. 9. Dialihbahasakan oleh Diah Tantri Dwiandani. Jakarta: Salemba Empat.

Pratiwi, Ni Luh Gede Arya Putri. 2015. Peran Lingkungan Sosial Dalam Memoderasi Ekuitas Merek Dan Esteem Needs Terhadap Niat Beli Konsumen.

Pujiadi, Babang. 2010. Studi Tentang Pengaruh Citra Merek Terhadap Minat Beli Melalui Sikap Terhadap Merek.

Purnamasari, Sinta. 2015. Brand Image Sebagai Mediasi Pengaruh Promosi, Harga Dan Sikap Konsumen Terhadap Keputusan Pembelian Jamu Nyonya Meneer Di Semarang Timur. Management Analysis Journal. Vol. 4. No. 3.

Putra, I Gusti Ngurah Bagus Adi Mas \& Ketut Rahyuda. 2016. Peran Brand 
Equity Memediasi Hubungan Iklan Dengan Keputusan Pembelian Konsumen. E-Jurnal Manajemen Unud, Vol. 5, No.12.

Rangkuti, Freddy. 2009. The power of Brands. Jakarta: PT. Gramedia Pustaka Utama.

Ridwan dan Kuncoro, Engkos Ahmad. 2011. Cara menggunakan dan memaknai Analisis Jalur Path (Path Analysis). Bandung: Alfabeta.

Rijswijk, Wendy Van., Lynn J. Frewer. 2008. Consumer Perceptions of Food Quality and Safety and Their Relation to Traceability. British Food Journal, Vol. 110. Issue: 10, pp: 1034-1046.

Rosyid, Aji Normawan., Handoyo Djoko W. dan Widayanto. 2013. Pengaruh Kualitas Produk, Citra Merek, Harga dan Iklan Terhadap Keputusan Pembelian Sepeda Motor Honda Revo (Studi Kasus pada Konsumen Sepeda Motor Honda Revo Astra Motor Kebumen). Jurnal Ilmu Administrasi Bisnis. Vol. 2 No. 3, pp: 1-8.

Santoso, Singgih. 2014. Statistik NonParametrik. Edisi revisi. Jakarta: PT. Elex Media Komputindo.

Sari, Rindang L., S.L. Mandey. A.S. Soegoto. 2014. Citra Merek, Harga Dan Promosi Pengaruhnya Terhadap Keputusan Pembelian Perhiasan Emas Pada Pt. Pegadaian (Persero) Cabang Manado Utara. Jurnal EMBA. Vol. 2. No. 2.

Setiadi, J. Nugroho. 2010. Perilaku Konsumen edisi revisi ke-4. Penerbit Kencana. Jakarta.

Setiadi, N. 2013. Perilaku Konsumen Konsep dan Implikasi untuk Strategi dan Penelitian Pemasaran. Kencana. Jakarta.

Shamout, M.D. 2016. The Impact of Promotional Tools on Consumer Buying Behavior in Retail Market. International Journal of Business and Social Science, 7(1): 75-85.

Situmorang, Irwanty L. 2017. Pengaruh Kualitas Produk Dan Iklan Terhadap Citra Merek Dan Keputusan Pembelian Produk Kecantikan Merek Pond's Pada Remaja Di Kota Pecan Baru. JOM Fekon, Vol. 4 No. 1.

Suciningtyas, W. 2012. Pengaruh Brand Awareness, Brand Image dan Media Komunikasi Terhadap Keputusan Pembelian. Management Analysis Journal, 1(1):1-8.

Sugiyono. 2013. Metode Penelitian Kuantitatif Kualitatif dan R\&D. Bandung: Penerbit Alfabeta. 
Sugiyono. 2014. Metode Penelitian Bisnis. Bandung: Alfabeta.

Sugiyono. 2015. Metode Penelitian Pendidikan (Pendekatan Kuantitatif, Kualitatif dan $R \& D)$ ). Penerbit CV. Alfabeta: Bandung.

Sukotjo, H., dan Radix, S.A. 2010. Analisa Marketing Mix-7P (Produk, Price, Promotion, Place, Partisipant, Process, dan Physical Evidence) terhadap Keputusan Pembelian Produk Klinik Kecantikan Teta di Surabaya, Jurnal Mitra Ekonomi dan Manajemen Bisnis, Vol. 1, No. 2, hal: 216-228.

Sumarwan, Ujang. 2011. Prilaku Konsumen Teori dan Penerapannya dalam Pemasaran. Ghalia Indonesia: Bogor

Sunyoto, Danang. 2012. Konsep dasar riset pemasaran dan perilaku konsumen. Penerbit CAPS. Yogyakarta.

Tanoni, Romy Victor. 2013. Pengaruh Iklan Terhadap Niat Beli Konsumen Melalui Citra Merek Dan Sikap Pada Minuman Isotonic Mizone Di Surabaya. Journal Wima.Vol.1, No. 6.

Wahyuni, Ainur. 2010. Pengaruh Brand Image Terhadap Keputusan Pembelian. Jurnal Administrasi Bisnis.

Wardi, Y. 2014. Membangun Personal Branding Melalui Iklan. Jurnal Dinamika Manajemen. 5 (2), pp: 100-109.

Wibisono, H. 2009. Manajemen Personalia. Jakarta: Argo Media Pustaka.

Widyatama, Rendra. 2007. Pengantar Periklanan. Yogyakarta: Pustaka Book Publisher.

Xian, Gou Li, dkk. 2011. Corporate-, Product-, and User-Image Dimensions and Purchase Intentions. Journal of Computers, (6)9: 18751879. 